\title{
Barrita Virus, a Novel Virus of the Patois Serogroup (Genus Orthobunyavirus; Family Peribunyaviridae)
}

\author{
Diana Fernández, ${ }^{1,2,3}$ William Marciel de Souza, ${ }^{4}$ Jesus A. Silvas, ${ }^{1,2,3}$ Eleanor R. Deardorff, ${ }^{1,2,3}$ Steven G. Widen, ${ }^{5}$ \\ Jose G. Estrada-Franco, ${ }^{6}$ Scott C. Weaver, ${ }^{1,2,3,7,8}$ Marcio Nunes, ${ }^{9}$ and Patricia V. Aguilar ${ }^{1,2,3,8 *}$ \\ ${ }^{1}$ Department of Pathology, University of Texas Medical Branch, Galveston, Texas; ${ }^{2}$ Center for Tropical Diseases, Galveston, Texas; ${ }^{3}$ Institute for \\ Human Infections and Immunity, Galveston, Texas; ${ }^{4}$ Virology Research Center, School of Medicine of Ribeirão Preto, Sao Paulo, Brazil; \\ ${ }^{5}$ Department of Biochemistry and Molecular Biology, Galveston, Texas; ${ }^{6}$ Centro de Biotecnologia Genómica, Instituto Politécnico Nacional \\ Reynosa, Tamaulipas, México; ${ }^{7}$ Department of Microbiology and Immunology, University of Texas Medical Branch, Galveston, Texas; ${ }^{8}$ World \\ Reference Center for Emerging Viruses and Arboviruses, Galveston, Texas; ${ }^{9}$ Center for Technological Innovation, Instituto Evandro
} Chagas, Ananindeua, Brazil

\begin{abstract}
During ecological investigations for arboviruses conducted in coastal Chiapas, Mexico, in 2007, isolate MP1078 was obtained from a pool of Psorophora varipes mosquitoes. Based on antigenic characterization, this isolate was classified as a strain of Patois virus (PATV) (Orthobunyavirus genus, Peribunyaviridae family). Recently, we conducted nearly complete genome sequencing of this isolate to gain further insight into its genetic relationship with other members of the Patois serogroup. Based on the genetic characterization, we determined that MP1078 contains S, M, and L genome segments that are genetically distinct from other viruses within the Patois serogroup. Serological analyses confirmed the taxonomic classification of MP1078 as a new virus and species within the Patois serogroup, and we propose the name Barrita virus (BITV).
\end{abstract}

The PATV was originally isolated from mosquitoes collected in Panama in $1961,{ }^{1}$ but it was also frequently isolated along the tropical Gulf coast of southeastern Mexico during ecological investigations in the 1960s. ${ }^{2,3}$ Zegla virus, another member of the Patois serogroup, was also frequently isolated from the same area as part of these ecological investigations. ${ }^{2,3}$ Given the frequent isolation of PATV, studies were conducted at the time to investigate human exposure to these viruses. These studies revealed the presence of hemagglutination inhibition and neutralizing antibodies to PATV in residents at the study site and in terrestrial wild mammals, including cotton rats, opossums, and raccoons. ${ }^{3}$ However, despite the serological evidence of human exposure to PATV, evidence of human disease caused by PATV and related viruses remains uncertain.

Ecological investigations conducted in South, Central, and North America have continued to frequently yield the isolation of viruses belonging to the Patois serogroup. ${ }^{4,5}$ In 2007, as part of ecological investigations for arbovirus in coastal Chiapas, Mexico, the isolation of virus strain MP1078 was described. ${ }^{6}$ This isolate was made from a pool of four Psorophora varipes mosquitoes collected in June 2007 in a mangrove habitat near the village of Isla Morelos in the municipality of Pijijiapan. As part of a systematic ecological investigation into the natural transmission cycle of Venezuelan equine encephalitis virus subtype IE (VEEVIE) in coastal Chiapas, mosquitoes and small mammals were collected at various times over the course of one calendar year. During that year, no VEEV-IE isolates were made, but two orthobunyaviruses, Nepuyo and Patois-like MP1078, were isolated from mosquito pools.

The mosquitoes were collected from a hamster-baited trap, identified morphologically, pooled, and stored in liquid nitrogen for approximately 2 weeks before being shipped to Galveston, Texas, for processing at BSL-3 at University of Texas Medical Branch (UTMB). Mosquito pools were homogenized with a mini-bead-beater, clarified by centrifugation, and the

*Address correspondence to Patricia V. Aguilar, Department of Pathology, University of Texas Medical Branch, 301 University Blvd., Galveston, TX 77555-0609. E-mail: pvaguila@utmb.edu supernatant was applied to Vero cells. After MP1078 caused primary and secondary cytopathic effects on Vero cells, the etiologic agent was identified as Patois-like virus by complement fixation assay. ${ }^{6}$

Recently, we conducted sequencing analyses of viruses belonging to the Patois serogroup viruses and obtained nearly complete genome sequencing information of the prototype viruses. $^{7}$ In an attempt to obtain additional sequence information for other Patois virus (PATV) strains isolated from field investigations and to provide additional evidence that MP1078 is in fact a strain of PATV, we conducted full genome sequencing and phylogenetic analyses of this isolate to determine its relationship to PATV and other members of the Patois serogroup. The isolate MP1078 was obtained from the World Reference Center for Emerging Viruses and Arboviruses and propagated in African green monkey kidney (Vero) cells. On the appearance of cytopathic effects, the cell culture supernatant was harvested and clarified by centrifugation, and viral RNA was extracted as previously described. ${ }^{8}$ The viral RNA was then fragmented, and a cDNA library was prepared and sequenced on a HiSeq 1000 instrument. Reads were quality-filtered and assembled using the de novo assembly strategy implemented in ABySS software. ${ }^{9}$ The longest contigs were selected and reads were mapped back to the contigs using bowtie 2 software, ${ }^{10}$ and then visualized with the Integrated Genomics Viewer ${ }^{11}$ to verify that the assembled contigs were correct. Additional details are available on request. Using this approach, we were able to obtain nearly complete S, M, and L segment sequences of MP1078, which cover all open reading frames. To determine the genetic relationship of MP1078 to PATV and other Patois group viruses, we carried out multiple sequencing alignments on both nucleotide and amino acid sequences of $S, M$, and $L$ RNA segments using the MAFFT software. ${ }^{12}$ Phylogenetic trees were constructed by the maximum likelihood (ML) method and inferred using IQ-TREE version 1.4.3 software under the best-fit model based on Bayesian information criterion determined by ModelFinder with 1,000 replicates. ${ }^{13,14}$ Our phylogenetic analyses revealed that MP1078 is in fact closely related to other 

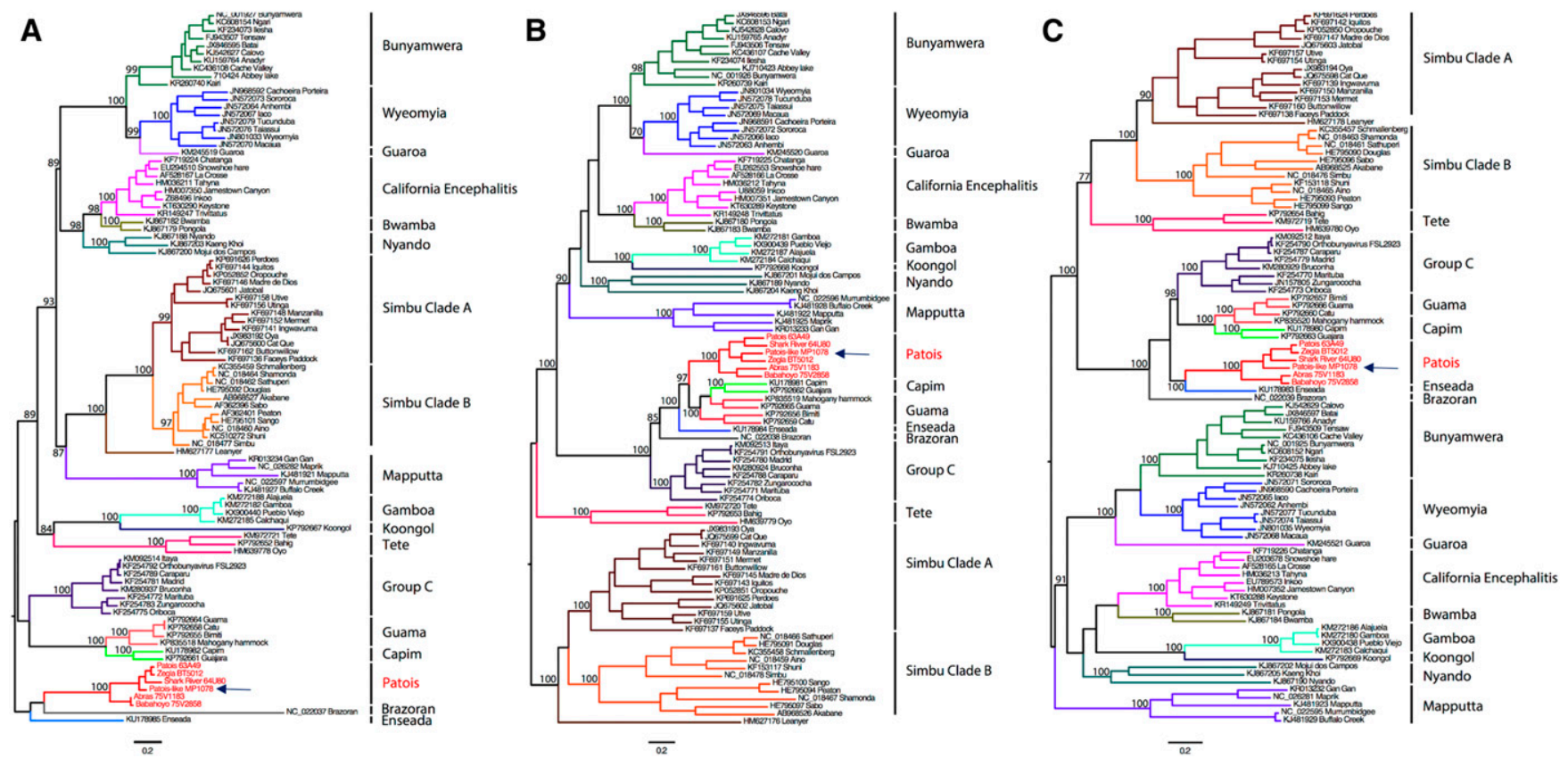

FIGURE 1. Maximum likelihood phylogenetic relationship of Patois serogroup viruses with other orthobunyaviruses. (A) $S$ segment based on TMP2+F+G4 nucleotide substitution model. (B) M segment based on GTR+F+l+G4 nucleotide substitution model. (C) $L$ segment based on TIM2+F+I+G4 nucleotide substitution model. Phylogenies are midpoint rooted and with proportional branches for clarity of presentation. The scale bar indicates the evolutionary distance in number of substitutions per amino acid substitutions/site, and the principal bootstrap support levels were indicated. The arrows indicate the position of the Patois-like MP1078 strain (Barrita virus).

viruses within the Patois serogroup (Figure 1). Although relationships derived from each genomic segment differed slightly, bootstrap values were not high enough to determine if these differences reflected reassortment. However, the S, M, and L RNA segments presented high genetic divergence (S segment $=10-23 \%$ nucleotides, $5-22 \%$ amino acid difference; $\mathrm{M}$ segment $=20-31 \%$ nucleotide, $8-29 \%$ amino acid difference; and L segment $=17-24 \%$ nucleotide, $4.5-16 \%$ amino acid difference) when compared with the sequences of other Patois serogroup viruses (Figure 2). In the past, the International Committee on Taxonomy of Viruses approved the classification of new species based on distinct biological characteristics of the respective virus. In recent years, the ICTV has refined its classification criteria for virus species demarcation. ${ }^{15-17}$ Specifically, ICTV has adopted sequence comparisons using pairwise sequence similarity and phylogenetic relationships as one of the primary criteria to define and distinguish virus taxa. ${ }^{16}$ Currently, the ICTV states that species within the genus Orthobunyavirus can be defined by less than $96 \%$ identity in the complete amino acid sequence of the $L$ protein (https://talk.ictvonline.org/ictv-reports/ictv_online_report/ negative-sense-rna-viruses/bunyavirales/w/peribunyaviridae/ 1238/genus-orthobunyavirus). Because MP1078 fulfill this criterion, it can be considered genetically distinct from other members within the Patois serogroup.

To gain further insights into the relationship of MP1078 to other Patois group viruses, we carried out one-way antigenic cross-neutralization analyses using antisera raised against

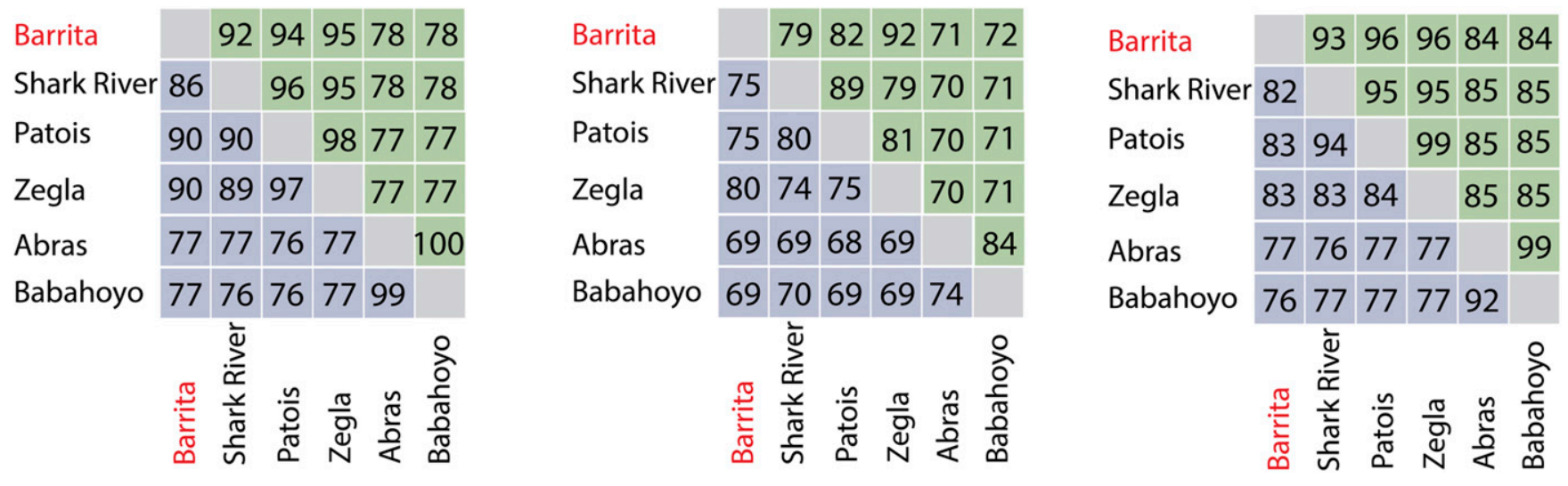

FIGURE 2. P-distance analysis of Barrita virus within the members of Patois serogroup. Distance based on the S segment (left panel), M segment (middle panel), and L segment (right panel) are shown. Distances in the nucleotide level are showed in purple and the amino acids level in green. Barrita and Zegla viruses share $95.5 \%$ amino acid sequence identity in the $L$ protein (depicted as $96 \%$ in the figure). This figure appears in color at www.ajtmh.org. 
TABLE 1

Neutralization of MP1078 by Patois serogroup virus antisera

\begin{tabular}{lccc}
\hline \multicolumn{4}{c}{ Mouse immune ascitic fluid } \\
\hline Virus & Patois & Shark River & Zegla \\
MP1078 (Barrita) & $<20$ & $<20$ & 640 \\
Patois & 160 & $<20$ & $<20$ \\
Shark River & 40 & 640 & $<20$ \\
Zegla & 20 & $<20$ & 10,240 \\
\hline
\end{tabular}

Neutralization titers are expressed as the dilution of mouse immune ascitic fluid antiserum inhibiting $80 \%$ of plaque-forming units.

the different Patois group viruses. Notably, we observed that these antisera displayed a minimum 4-fold difference in neutralization titers among these viruses, indicating that MP1078 is antigenically distinct from other Patois serogroup viruses (Table 1).

In summary, in this study, we have provided genetic and antigenic support for the classification of MP1078 as a new virus and species in the Patois serogroup. Thus, based on the current ICTV criteria for species demarcation, we propose the name Barrita virus (BITV) for this newly identified virus within the Patois serogroup. Further investigation into the public health impact of this virus is warranted.

Received December 6, 2019. Accepted for publication March 2, 2020. Published online May 26, 2020.

Financial support: This study was supported by the National Institutes of Health (NIH) grants number 5D43TW010331-04, F31 Al124662-01, and R24 Al120942. W. M. S. was supported by the Fundação de Amparo à Pesquisa do Estado de São Paulo-FAPESP grants no. 17/ 13981-0 and MRTN was supported by the Conselho Nacional de Desenvolvimento Científico e Tecnológico grant numbers 302032/ 2011-8 and 200024/2015-9.

Authors' addresses: Diana Fernández, Jesus A. Silvas, Eleanor R. Deardorff, Patricia V. Aguilar, Jose G. Estrada-Franco, and Scott C. Weaver, Department of Pathology, University of Texas Medical Branch, Galveston, TX, E-mails: dpfernan@utmb.edu, jsilvas@gsu.edu, eleanorhutterer@gmail.com, pvaguila@utmb.edu,joseestradaf@ hotmail.com and sweaver@utmb.edu. William Marciel de Souza, Virology Research Center, School of Medicine of Ribeirão Preto, Sao Paulo, Brazil, E-mail: wmarciel@hotmail.com. Steven G. Widen, Department of Biochemistry and Molecular Biology, University of Texas Medical Branch, Galveston, TX, E-mail: sgwiden@utmb.edu. Marcio Nunes, Center for Technological Innovation, Instituto Evandro Chagas, Ananindeua, Brazil, E-mail: marcionunesbrasil@yahoo.com.br.

\section{REFERENCES}

1. Srihongse $S$, Galindo $P$, Grayson MA, 1966. Isolation of group C arboviruses in Panama including two new members, Patois and Zegla. Am J Trop Med Hyg 15: 379-384.
2. Zarate ML, Geiger RH, Shope RE, Scherer WF, 1968. Intergroup antigenic relationships among arboviruses manifested by a Mexican strain of Patois virus and viruses of the Bunyamwera, C, California, Capim and Guama groups. Am J Epidemiol 88: 273-286.

3. Scherer WF, Anderson K, Dickerman RW, Ordonez JV, 1972. Studies of Patois group arboviruses in Mexico, Guatemala, Honduras, and British Honduras. Am J Trop Med Hyg 21: 194-200.

4. Scherer WF, Dickerman RW, Ordonez JV, Seymour C, Kramer LD, Jahrling PB, Powers CD, 1976. Ecologic studies of Venezuelan encephalitis virus and isolations of Nepuyo and Patois viruses during 1968-1973 at a marsh habitat near the epicenter of the 1969 outbreak in Guatemala. Am J Trop Med Hyg 25: 151-162.

5. Scherer WF, Dickerman RW, Cupp EW, Ordonez JV, 1985. Ecologic observations of Venezuelan encephalitis virus in vertebrates and isolations of Nepuyo and Patois viruses from sentinel hamsters at Pacific and Atlantic habitats in Guatemala, 1968-1980. Am J Trop Med Hyg 34: 790-798.

6. Deardorff ER, Forrester NL, Travassos da Rosa AP, EstradaFranco JG, Navarro-Lopez R, Tesh RB, Weaver SC, 2010. Experimental infections of Oryzomys couesi with sympatric arboviruses from Mexico. Am J Trop Med Hyg 82: 350-353.

7. Aguilar PV, Marciel de Souza W, Silvas JA, Wood T, Widen S, Fumagalli MJ, Nunes MRT, 2018. Genetic characterization of the patois serogroup (genus Orthobunyavirus; family Peribunyaviridae) and evidence that Estero real virus is a member of the genus Orthonairovirus. Am J Trop Med Hyg 99: 451-457.

8. Hontz RD et al., 2015. Itaya virus, a novel Orthobunyavirus associated with human febrile illness, Peru. Emerg Infect Dis 21: 781-788.

9. Simpson JT, Wong K, Jackman SD, Schein JE, Jones SJ, Birol I, 2009. ABySS: a parallel assembler for short read sequence data. Genome Res 19: 1117-1123.

10. Langmead B, Salzberg SL, 2012. Fast gapped-read alignment with Bowtie 2. Nat Methods 9: 357-359.

11. Robinson JT, Thorvaldsdóttir H, Winckler W, Guttman M, Lander ES, Getz G, Mesirov JP, 2011. Integrative genomics viewer. Nat Biotechnol 29: 24-26.

12. Katoh K, Standley DM, 2013. MAFFT multiple sequence alignment software version 7: improvements in performance and usability. Mol Biol Evol 30: 772-780.

13. Kalyaanamoorthy S, Minh BQ, Wong TKF, von Haeseler A, Jermiin LS, 2017. ModelFinder: fast model selection for accurate phylogenetic estimates. Nat Methods 14: 587-589.

14. Nguyen LT, Schmidt HA, von Haeseler A, Minh BQ, 2015. IQTREE: a fast and effective stochastic algorithm for estimating maximum-likelihood phylogenies. Mol Biol Evol 32: 268-274.

15. Adams MJ et al., 2017. Changes to taxonomy and the international code of virus classification and nomenclature ratified by the international committee on taxonomy of viruses (2017). Arch Virol 162: 2505-2538.

16. Lefkowitz EJ, Dempsey DM, Hendrickson RC, Orton RJ, Siddell SG, Smith DB, 2018. Virus taxonomy: the database of the international committee on taxonomy of viruses (ICTV). Nucleic Acids Res 46: D708-D717.

17. Simmonds $P$ et al., 2017. Consensus statement: virus taxonomy in the age of metagenomics. Nat Rev Microbiol 15: 161-168. 